Kepros, P. G., \& Bourne, L. E., Jr. Identification of biconditional concepts: Effects of number of relevant and irrelevant dimensions. Canadian Journal of Psychology, 1966 30, 198-207.

Laughlin, P. R. Focusing strategy for eight concept rules. Journal of Experimental Psychology, 1968, 77, 661-669.

Laughlin, P. R., \& Jordan, R. M. Selection strategies in conjunctive, disjunctive, and biconditional concept attainment. Journal of Experimental Psychology, 1967, 75, 188-193.
Taplin, J. E., \& Jeeves, M. A. Strategies in concept learning. Program on Concept Learning Report No. 19, Institute for the Study of Intellectual Behavior, University of Colorado, 1972, 1-54.

(Received for publication February 16, 1974.)

\title{
Differential conditioning and contrast effects in humans*
}

\author{
RICHARD S. CALEF $\dagger$, RUTH ANN CALEF, GRANT BUTTERMORE, and SUSAN J. THOMAS \\ West Virginia Wesleyan College, Buckhannon, West Virginia 26201
}

\begin{abstract}
The present study investigated discrimination $\mathrm{S}+$ contrast effects as a function of the magnitude of reward in $\mathrm{S}$ - while attempting to alleviate ceiling effect and decision time problems present in previous animal and human simultaneous contrast studies. In the study, three groups of human Ss recrived differential reward conditioning for accurately tracing numbered-nonnumbered star patterns, whereas a control group received only large reward in both discriminanda. The results replicated the findings of a previous animal study which also attempted to control for ceiling and decision time variables in that a positive S+ contrast effect was found. Also, the positive S+ contrast effect increased as the magnitude of reward in $\mathrm{S}$ - decreased. The results seem to support a perceptual analysis of contrast effects.
\end{abstract}

Previous studies (e.g., Bower, 1961; Ludvigson \& Gay, 1966) have shown that performance of rats to the negative discriminandum $\left(\mathrm{S}_{-}\right)$in differential conditioning is influenced by the reinforcement contingencies associated with the positive discriminand um $(\mathrm{S}+)$. Generally, these studies demonstrate that the $\mathrm{S}$ - performance of differentially

*This paper is sponsored by James H. McHose, who takes full editorial responsibility for it.

†Requests for reprints should be sent to Richard S. Calef, Department of Psychology, West Virginia Wesleyan College, Buckhannon, West Virginia 26201. reinforced (discrimination) groups is depressed relative to that of nondiscrimination control groups receiving small reinforcement in "S+" and "S-" (negative Scontrast). Previous studies have also shown a significant depression (Henderson, 1966; MacKinnon, 1967) of S+ speeds for discrimination Ss relative to that of nondiscrimination control Ss receiving large reinforcement in "S+" and "S-" (negative S+ contrast).

Little information has been available concerning how human Ss respond to stimuli associated with contrasting magnitude of reward. Recently, however, Calef et al 
(1971) have reported that Ss which received differential reward conditioning for accurately tracing numbered-nonnumbered star patterns displayed a significant negative $S$ - contrast effect and a trend towards a significant negative $\mathrm{S}+$ contrast effect. Calef et al (1972) also showed the negative contrast effect in humans to increase as a function of the magnitude of reward in S+. This finding was obtained by Ludvigson \& Gay (1966) with infrahuman Ss. Lastly, Lamberth et al (1972) found both negative S+ and S- contrast effects using human barpress conditioning with social reinforcers.

In essence, the previous results from animal and human research seem to support theoretical approaches that predict both negative S+ and $\mathrm{S}$ - contrast effects and attribute the effects to an emotional phenomenon (inhibition) which occurs as a result of receiving a reduction in magnitude of reward (Black, 1968). In addition, the previous results seem nonsupportive of perceptual theories which treat reward magnitude mainly in terms of its stimulus properties and predict positive S+ and negative S- contrast effects (Collier \& Marx, 1959; Dunham, 1968; Helson, 1966). However, Mellgren et al (1972) argued that previous research using a differential conditioning procedure to examine contrast effects in the runway was inadequate due to the operation of a ceiling effect and/or a decision-time problem. According to Mellgren et al (1972), the failure to find a positive $S+$ contrast effect (experimental Ss running faster to $\mathrm{S}+$ than control Ss running to large reward on all trials) may have occurred because the large reward control Ss were displaying extremely rapid speeds approximating the physiological limits of the organism. Also, previous research designs may have precluded the observance of positive contrast by initiating a decision-making problem for experimental Ss only. Previous studies used a neutral gray startbox, thus preventing experimental Ss from "deciding" whether to run slow or fast until speeds were actually being recorded in the $\mathrm{S}-$ or $\mathrm{S}+$, respectively. With the addition of decision time to running time for experimental Ss, positive contrast becomes difficult to demonstrate, for the control Ss have no decision to make since both discriminanda lead to the same reward.

Mellgren et al (1972) attempted to obtain a positive St contrast effect in differential conditioning by imposing delay of reinforcement for all Ss which, in turn, should have prevented running speeds from reaching a ceiling, and by minimizing the decision time while the Ss were actually performing the response. The latter was accomplished by correlating the brightness of the startbox with its respective runway. The results of Mellgren et al (1972) displayed a reliable positive and negative contrast effect. Mellgren (1972) contended that previous theories (e.g., Black, 1968; McHose, 1970) designed to predict only negative contrast effects were inadequate.

It should be mentioned that the procedure utilized by
Calef et al (1971) in showing a negative S+ contrast effect with human Ss also may have precluded the observation of positive contrast. In the study, the control Ss almost attained perfection in star tracing during terminal acquisition, hence, possibly achieving a physiological and/or task ceiling, thus preventing the experimental Ss from "overshooting" the asymptotic performance of the control Ss. Also, the Ss were instructed to commence tracing the stars before observing the discriminandum of that trial, thus adding decision time to tracing time. Hence, the results of Calef et al (1971) may have been indicative of something other than an inhibitory mechanism.

The purpose of the present study was to ascertain whether the formulations of Black (1968) and McHose (1970) may also be inadequate for human Ss with respect to the S+ contrast effect. The present study investigated $\mathrm{S}+$ contrast while attempting to (a) minimize the development of a physiological and/or task ceiling by moderately increasing task difficulty, and (b) minimizing the decision time by confronting the Ss with the discriminandum prior to tracing. Incidentally, $\mathrm{S}+$ contrast as a function of the magnitude of reward in $\mathrm{S}$ - was also examined.

\section{METHOD}

The Ss were 20 male and 20 female undergraduate students enrolled in an introductory psychology course. The Ss were randomly assigned to each of four equal-sized groups.

The materials consisted of 560 star patterns and 40 Noblot black ball-point pens. Each $S$ was required to trace 14 star patterns (14 trials) with the less preferred hand. The Ss were given only $15 \mathrm{sec}$ to complete as many 1 -in. segments of each star (20 segments to a star) as was possible without touching the borderline. In order to minimize the development of a physiological and/or task ceiling, the pathway of the star that had to be traced was narrowed from the $.635 \mathrm{~cm}$ used in Calef et al (1971) to $.3175 \mathrm{~cm}$. The intertrial interval was $2 \mathrm{~min}$. In order to separate decision time from tracing time, Ss were given $5 \mathrm{sec}$ to observe the discrimination before tracing.

Before the experiment, all Ss were told that they could obtain extra points towards their course grade by successfully tracing a number of star patterns, and that 50 points accumulated in the experiment were equivalent to 1 extra point in the course. Group 8-0 received a large number of points (8) in the presence of a particular discriminandum $(\mathrm{S}+)$, and no points in the presence of another discriminandum $(\mathrm{S}-$ ) for completing a segment of a star without touching the border. Following each trial, the Ss were informed in writing as to whether they had received points and, if so, the amount of which they received. For half the Ss, large (L) reward (8 points) was correlated with a numbered star $(\mathrm{S}+)$ and no $(\mathrm{N})$ reward was correlated with a nonnumbered star $(\mathrm{S}-)$. For the other half of the $\mathrm{Ss}$, the contingencies were reversed. Hence, each $S$ in Group 8-0 traced seven $\mathrm{S}+$ and seven $\mathrm{S}-$ stars. Each $\mathrm{S}$ was assigned randomly to one of 10 different schedules of reward (e.g., LNNLLNNLNLLNLN). Groups 8-1 and 8-4 received the same treatment as Group 8-0 except for receiving 1 point and 4 points for accurately tracing each segment of their $S-$ stars, respectively. In the large reward control group, $10 \mathrm{Ss}$ received large reward ( 8 points) for accurate completion of both discriminanda. In order to control for trial position, 10 different schedules of "St" and "S-" were assigned randomly to control Ss regardless of the fact that they did not receive differential 
Table 1

Group Mean Scores Over the First Three (Early) and the Last Three (Late) $S+$ and $S-$ Trials for Groups 8-8, 8-4, 8-1, and 8-0

\begin{tabular}{cccccc} 
& \multicolumn{2}{c}{ Early Stage } & & \multicolumn{2}{c}{ Late Stage } \\
\cline { 2 - 3 } \cline { 5 - 6 } Group & S+ & S- & & S+ & S- \\
\hline $8-8$ & 33 & 32 & & 40 & 42 \\
$8-4$ & 31 & 33 & & 46 & 32 \\
$8-1$ & 30 & 29 & 65 & 20 \\
$8-0$ & 27 & 29 & 75 & 15 \\
\hline
\end{tabular}

reward. Course grade averages between groups at the time of testing were equated to insure greater probability of comparable motivation between groups. The performance of Ss was determined by assigning 10 points for each completed segment of a star if the border was not touched, and 0 points for completed segments, the borders of which were touched, and uncompleted segments.

\section{RESULTS}

Table 1 shows group mean star-tracing performance over the first three (early) and last three (late) S+ and $\mathrm{S}-$ trials for Groups 8-8, 8-4, 8-1, and 8-0. As can be seen in Table 1, no discrimination occurred during the early trials. Groups $8-4,8-1$, and 8-0 performed better on $\mathrm{S}+$ than on $\mathrm{S}-$ trials during the late stage. Within-group $t$ tests of the data from Groups 8-4, 8-1, and 8-0 during the late stage yielded a significant difference between the $\mathrm{S}+$ and $\mathrm{S}-$ scores $(\mathrm{t}=1.94, \mathrm{df}=$ $9, \mathrm{p}<.05 ; \mathrm{t}=3.16, \mathrm{df}=9, \mathrm{p}<.01 ; \mathrm{t}=4.75, \mathrm{df}=9$, $\mathrm{p}<.005$, respectively).

A one-way analysis of variance of the $\mathrm{S}+$ data for Groups 8-8, 8-4, 8-1, and 8-0 over the late stage yielded significance $(F=9.54, \mathrm{df}=36, \mathrm{p}<.01)$. Subsequent Newman-Keuls paired-comparison tests of the S+ scores over the late stage showed Group 8-4 not to perform significantly better than Group 8-8 $\left(\mathrm{Q}_{2}=1.88\right.$, $\mathrm{df}=36$, $\mathrm{p}>.05)$. Groups 8-1 and 8-0 scored higher than Group 8-8 $\left(\mathrm{Q}_{3}=7.87, \mathrm{df}=36, \mathrm{p}<.01 ; \mathrm{Q}_{4}=10.94, \mathrm{df}\right.$ $=36, p<.01$, respectively). Also, Group $8-1$ produced better scores than Group 8-4, and Group 8-0 performed significantly better than Group 8-1 $\left(\mathrm{Q}_{2}=5.94, \mathrm{df}=36\right.$, $\mathrm{p}<.01 ; \mathrm{Q}_{2}=3.13, \mathrm{df}=36, \mathrm{p}<.05$, respectively). A one-way analysis of variance of the data over the early stage yielded nonsignificance $(\mathrm{F}<1)$.

\section{DISCUSSION}

The present data indicate that performance in the presence of the $\mathrm{S}+$ discriminandum is influenced by the reward received in the presence of the $\mathrm{S}$ - discriminandum for human Ss. The results also showed that the smaller the reward in the $\mathrm{S}-$, the better was the performance to the $S+$. The present finding of a positive S+ contrast effect is supportive of that of Mellgren et al (1972), which implies that previous failures to obtain this effect were probably due to (a) a ceiling effect, or (b) a decision-time problem, or both. Although the present study does not permit a conclusive statement as to the minimum requirement for a positive $\mathrm{S}+$ contrast effect, the results do indicate that the negative $\mathrm{S}+$ contrast effect was, at best, an artifact of previous designs. It should be mentioned, however, that "raising the ceiling" apparently was the minimum requirement for producing positive contrast in the runway using the Crespi (1942) shift in magnitude of reward procedure (Shanab et al, 1969; Shanab \& Ferrell, 1970; Mellgren, 1970).

According to Mellgren et al (1972), theories (e.g., Black, 1968; McHose, 1970) designed to predict negative S+ and Scontrast effects are inadequate since positive contrast can be obtained when ceiling effect and/or decision-time problems are alleviated. The authors contended that the data better supports the perceptual theories (Collier \& Marx, 1959; Dunham, 1968; Helson, 1966) of contrast effects which predict "symmetrical effects for contrasted conditions of reward" (Mellgren et al, 1972). In view of the present results, perceptual theory would seem to be the best explanation for animal and human contrast effects.

It should also be mentioned that the present results indicate that the mechanisms involved in human successive contrast effects are similar to those involved in human simultaneous contrast effects. Weinstein $(1970,1971)$ found both negative and positive contrast using a Crespi (1942) design while decreasing and increasing magnitude of reward, respectively.

\section{REFERENCES}

Black, R. W. Shifts in magnitude of reward and contrast effects in instrumental and selective learning: A reinterpretation. Psychological Review, 1968, 75, 114-126.

Bower, G. H. A contrast effect in differential conditioning. Journal of Experimental Psychology, 1961, 62, 196-999.

Calef, R. S., Calef, R. A. B., Bone, R. N., \& Buttermore, G. A human analogue of discrimination contrast: $S$ - contrast as a function of magnitude of S+. Psychonomic Science, 1972, 29, 118-119.

Calef, R. S., Calef, R. A. B., Bone, R. N., Thomas, T., \& Fox, P. A. A human analogue of discrimination contrast. Psychonomic Science, 1971, 23, 191-192.

Collier, G., \& Marx, M. H. Changes in performance as a function of shifts in the magnitude of reinforcement. Journal of Experimental Psychology, 1959, 57, 305-309.

Crespi, L. P. Quantitative variations of incentive and performance in the white rat. American Journal of Psychology, 1942, 55, 467-517.

Dunham, P. J. Contrasting conditions of reinforcement: A selective critique. Psychological Bulletin, 1969, 69, 295-315.

Helson, H. Some problems in motivation from the point of view of the theory of adaptation level. Nebraska Symposium on Motivation, 1966, 14, 137-182.

Henderson, $K$. Within-subjects partial reinforcement effects in acquisition and in later discrimination training. Journal of Experimental Psychology, 1966, 72, 704-713.

Lamberth, J. L., Gay, R. G., \& Dyck, D. G. Differential reward magnitude and human conditioning with social reinforcers. Psychonomic Science, 1972, 28, 231-299.

Ludvigson, H. W., \& Gay, R. G. Differential reward conditioning: $S-$ contrast as a function of the magnitude of S+. Psychonomic Science, 1966, 5, 289-290.

Mackinnon, J. R. Interactive effect of the two rewards in a differential magnitude of reward discrimination. Journal of Experimental Psychology, 1967, 75, 329-338.

McHose, J. H. Relative reinforcement effects: $S_{1} / S_{1}$ and $S_{1} / S_{1}$ paradigms in instrumental conditioning. Psychological Review, $1970,77,135-146$

Mellgren, R. L. Positive and negative contrast effects using delayed reinforcement. Learning \& Motivation, 1972, 3 , 185-193.

Mellgren, R. L., Wrather, D. M., \& Dyck, D. G. Differential conditioning and contrast effects in rats. Journal of Comparative \& Physiological Psychology, 1972, 80, 478-483.

Shanab, M. E., \& Ferrell, H. J. Positive contrast in the Lashley maze under different drive conditions. Psychonomic Science, 1970, 20, 31-32.

Shanab, M. E., Sanders, R., \& Premack, D. Positive contrast in the runway obtained with delay of reward. Science, 1969, 164, 724-725.

Weinstein, L. Magnitude of incentive contrast as a function of amount of verbal reward change. Psychonomic Science, 1970 , $21,65-66$.

Weinstein, L. Effect of an increment in incentive magnitude on instrumental responding and repeated increases in reward magnitude in humans. Psychonomic Science, 1971, 25, 235-237.

(Received for publication February 14, 1974.) 